\title{
Quenching of Spontaneous Emission Coefficients
}

\section{in Plasmas}

Y. Chung, P. Lemaire, and S. Suckewer

PPPL -2.472

DEB8 003465

\author{
Princeton Plasma Physics Laboratory \\ Princeton, New Jersey 08544
}

\section{DISCLAIMER}

\begin{abstract}
This report was prepared as an accoust of work sponsored by an agency of the United States Government. Neilher the United States Govemment nor any agency thereor, nor any of their employear, makes any warranty, express or implied, or assumes any legal liability or responsibiliny for the accuracy, completeness, or uscfulness of any infotmation, apparalus, product, or process disclosed, or ecpresents that its use would not infringe privately owned rights. Reference herein to any specific commercial product, process, or service by trade name, irademark, manulacturee, or otherwise does not necossarily constitute or imply its erdorsement, recom. mendation, or favoring by the United States Government or any agency thereol. The views and opinions of authors expressed hertin do not necessarily state or reflect those of the United States Government or any agency therear.
\end{abstract}

\section{Abstrac1}

We have observed changing Einstein coefficients of spontaneous emission as a function of electron density in $\mathrm{CO}_{2}$ laser-produced plasmas. These measurements are based on the intensity branching ratio of CIV lines 5801-5812 $\AA$ and 312.41-312.46 $\AA$ which share a common upper level. Similar observations for $\mathrm{CII}$ lines are also discussed.

\section{MASTER

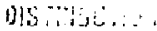


The coefficient of spontaneous emission, A, also called the Einstein coefficient, is considered to be one of the basic constants of a given transition in an atom or an ion. Therefore, the spectral line intensity $I_{\mathrm{sm}}$ (in photons) for $\mathrm{n} \rightarrow \mathrm{m}$ transition is always expressed as being proportional to the spontaneous emission coefficient $A_{n m}$ (in sec ${ }^{-1}$ ) for an optically thin plasma (e.g., see Ref. 1):

$$
I_{n m}=k_{n}(r) N_{n}\left(N_{e}, T_{e}\right) A_{n m},
$$

where $k_{n}(r)$ is a geometrical factor, $N_{n}$ (in cm ${ }^{-3}$ ) is the population density of the upper level $n$, and $N_{e}$, and $T_{e}$ are electron density and temperature, respectively. It is always assumed that the plasma electron density has no effect on the $A_{n m}$ coefficients and determines $N_{n}$ through collisional processes. This has led to the development of modeis for the calculation of hevel populations, particularly collisional-radiative models (e.g., see Ref. 2). Also, as a consequence of this assumption, the so-called branching ratio technique was developed for absolute intensity measurements of spectral lines in the vacuum ultraviolet (VUV) wavelength region. ${ }^{3}$ From Eq. (1), it follows immediately that for optically thin lines with a common upper level [at therefore the same $N_{n}$ and $k_{n}(r)$ ] and different lower levels, the ratio of line intensities is equal to the ratio of the corresponding A-coefficients, that is,

$$
\mathrm{R}=\mathrm{I}_{\mathrm{nm}} / \mathrm{I}_{\mathrm{nk}}=\mathrm{A}_{\mathrm{nm}} / \mathrm{A}_{\mathrm{nk}}
$$

In this way, if the ratio, $R$, of A-coefficients is known for a pair of lines and if the intensity of one line (e.g., for wavelength $\lambda>2000 \AA$ ) is measured, one may obtain the intensity of the second line (e.g., in VUV). Of course, this technique can be reversed, i.e., from measurements of the intensity ratio of two lines in an optically thin plasma, the ratio $R$ and thus either of the corresponding spontaneous emission coefficients, $\mathrm{A}$, can be deduced.

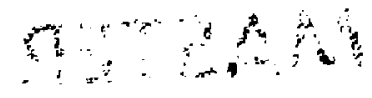


Approximately three years ago, during the intensity calibrationof VUV spectrometers by the branching ratio technique for $\mathrm{X}$-ray laser experiments, we observed an unexplainable discrepancy between calibrations using a $\mathrm{CO}_{2}$ laser and those using a spark discharge for producing plasma. One of us (S.S.) came to the hypothesis that in higher density plasmas (in our case laser-produced plasmas) spontaneous emission coefficients may decrease as a result of electrons interacting with atoms and ions. Such an effect should be larger for transitions with a longer lifetime (smaller A), in contrast to the effect of selfabsorption. In this case it was expected that the branching ratio should change very significantly with increasing electron density.

We decided to study experimentally the quenching of spontaneous emission coefficients in plasmas using CIV lines with a common upper level 3p $2 \mathrm{P}$ (denoted here as level 3) and transitions to levels $3 s^{2} S$ (5801.5 $\AA$ and $5812.1 \AA$ lines) and $2 s^{2} S(312.42 \AA$ and $312.46 \AA$ lines) which are denoted as levels 2 and 1 , respectively. We chose these lines because in our experiment, radiation from $\mathrm{Li}-$ like CIV ions was intense in the plasma created by a relatively low power $\mathrm{CO}_{2}$ laser $(\sim 10 \mathrm{~J}, 150 \mathrm{nsec}$ pulse and $500 \mu$ diameter focal spot) and therefore the CIV lines in the visible region of the spectra were easy to monitor. The coefficients of spontaneous emission for these transitions are $\mathrm{A}_{32}=0.32 \times$ $10^{8} \mathrm{sec}^{-1}$ and $A_{31}=45.6 \times 10^{8} \mathrm{sec}^{-1}$, respectively $\mathrm{y}^{4}$ and the statistical weights are $\mathrm{g}=4$ and 2 for the sublevels of level 3 .

The experimental arrangement is presented in Figs. $1 \mathrm{a}$ and $1 \mathrm{~b}$. The $\mathrm{CO}_{2}$ laser beam is focused onto a carbon target by a $\mathrm{NaCl}$ lens of focal length $\mathrm{f}=50 \mathrm{~cm}$. Because near the target $(\mathrm{d}=0-20 \mu \mathrm{m})$ the plasma electron density is ciose to that of the solid state $\left(-10^{23}\right.$ $\mathrm{cm}^{-3}$ ) and decreases very rapidly (due to expansion) with distance $d$ to the critical electron density for the $\mathrm{CO}_{2}$ laser, $\mathrm{N}_{\mathrm{e}} \approx 10^{19} \mathrm{~cm}^{-3}$, and below it with further increasing $\mathrm{d}$, the most significant changes of spontaneous emission were expected close to the target. Therefore, 
in order to observe only a limited region of the plasma at a chosen distance from the target, a slit $S=200 \mu$ was placed at a distance of $15 \mathrm{~mm}$ from the plasma.

The size of the slit was chosen as a trade-off between spatial resolution and detected signal strength. The slit $\mathrm{S}$, being attached to the vacuum chamber, was unmovable and only the target could be moved by a miczometric vacuum feedthrough perpendicular to the laser beam and parallel to the slit $S$. The target had several steps and by moving the target the laser beam could initiate plasma at different distances $d$ from the viewing path through slit S (see insert for Fig. 1a), thereby providing plasmas with a range of electron densiries. The interacrion of the $\mathrm{CO}_{2}$ laser beam with the target was practically the same for different distances, $d$, as the depth of focus of the laser beam was much larger than the maximuni change of $d$.

In order to provide simultaneous measurements of line intensities in VUV and Visible-UV spectra from exactly the same region of the plasma, a grazing incidence $1.5 \mathrm{~m}$ vacuum spectrometer, McPherson 252, was significantly modified and combined with a $0.5 \mathrm{~m}$ Ebert-Fastie type Jarrell-Ash air spectrometer $(\lambda \geq 2000 \AA)$. In this new type of visible-UV/VUV spectrometer, the plasma radiation, after passing the entrance slit, was partially diffracted and partially reflected (zeroth-order) by the VUV spectrometer's grating (1200 $\mathrm{gr} / \mathrm{mm}$ ). The diffracted beam was focused on the Rowland circle, whereas the zeroth-order beam was directed by the mirror into the Visible-UV spectrometer with its own nomal incidence grating (1200 gr/mm). Signals in Visible-UV and in VUV regions were monitored by multichannel detectors (1024 pixels each).

In Figs. $2 \mathrm{a}$ and $2 \mathrm{~b}$ are shown typical computer outputs for spectra in the vicinity of (a) CIV $312 \AA$ and (b) 5801-5812 $\AA$ lines with the target surface at distances $d=0.2 \mathrm{~mm}$ and $1.0 \mathrm{~mm}$ from the farther edge of the slit $S$. The width of the target measured along the line of sight. $w$, was $1 \mathrm{~mm}$. The results of the measurements of the intensity branching ratio $R=I_{32} / I_{31}$ as a function of distance, $d$, from target (hence as a function of electron 
densiry $N_{e}$ ) for different target widths ( $w=0.35,0.42,1.0$, and $4.1 \mathrm{~mm}$ ) are presented in Fig. 3. The electron density was measured from Stark broadening of the CIV $5801 \AA$ line using the quasi-static approximation $\Delta \lambda_{s}=\alpha \times N_{e}^{2 / 3}$ (Ref. 1). Instrumental broadening $\Delta \lambda_{\text {ins }}=1.6 \AA$ was measured with a low pressure $\mathrm{Hg}$-lamp. The coefficient $\alpha$ was determined by the measured value of $\Delta \lambda_{s}=6 \AA$ at $1.5 \times 10^{18} \mathrm{~cm}^{-3}$ in Ref. 5 . For a narrow target, $w=0.35 \mathrm{~mm}$, and $\mathrm{d} \geq 0.5 \mathrm{~mm}$, where the effect of self-absorption is negligible, the intensity branching ratio, $R$, is equal to the spontaneous emission coefficients ratio $A_{32} / A_{31}$ ( $A_{V I S} / A_{V U V}$ ). The intensities $I_{31}(V U V)$ and $I_{32}$ (VIS) were obtained from the multichannel detector signals (see Fig. 2) by integrating over the profile of the $312.42-312.46 \AA$ and 5801.5-5812.1 $\AA$ lines after subtracting respective backgrounds. The intensities of $312 \AA$ lines increased with decreasing $d$, as expected, due to the increasing abundance of CIV and rise of $\mathrm{N}_{\mathrm{e}}$, whe:eas the visible lines $5801-5812 \AA$ increased significantly less and close to the surface of the target $(\mathrm{d} \leq 0.2-0.3 \mathrm{~mm})$ started to decrease. The intensity ratio of the two lines $I_{5801} I_{5812}$ was practically the same for all distances and close to its theoretical value 2:1, indicating that these lines are optically thin.

All measurements of the ratio, $R$, were normalized to the theoretical value $4=7 \times$ $10^{-3}$ for nonperturbed ions. For wider targets $(w=1.0 \mathrm{~mm}, 4.1 \mathrm{~mm})$ normalization was done at a distance of $d=1.5$ and $1.2 \mathrm{~mm}$, respectively, in order to avoid the effect of selfabsorption on the $312 \AA$ lines. For narrower targets, normalization was done at a smaller distance, $\mathrm{d}=1 \mathrm{~mm}$

The effect of self-absorption on the VUV lines is evident in the wider targets from the higher ratio, $R$, and its peak at $d=0.6 \mathrm{~mm}$ ( $w=1.0$ and $4.1 \mathrm{~mm}$ ). For these targets, selfabsorption increases with increasing $\mathrm{N}_{\mathrm{e}}$, therefore, only when the effect of quenching of the coefficient of spontaneous emission for visible lines becomes dominant at $d<0.5 \mathrm{~mm}$ $\left(N_{e}>10^{18} \mathrm{~cm}^{-3}\right)$ can the rapid decrease of branching ratio, $R$, be observed. On the other hand, if the electron density and hence $R=A_{32} / A_{31}$ is kept constant ( $d=$ constant) and the 
width, $w$, of the target is changed, the line intensity ratio $I_{32} / I_{31}$ changes due to selfabsorption of VUV lines mainly, as is demonstrated by the top curve in Fig. 3 (this intensity ratio in Fig. 3 is multiplied by 1.4 in order to separate the curves). These measurements were done for $d=0.5 \mathrm{~mm}$ using a wedge carbon target in which the width varied from $w=0.2 \mathrm{~mm}$ up to $1.3 \mathrm{~mm}$.

Very recently, the effect of quenching spontaneous emission was also observed in $\mathrm{CIII}$ in measurements of the intensity ratio of $5696.0 \AA$ (3d ${ }^{1} \mathrm{D}-3 \mathrm{p}^{1} \mathrm{P}^{0}$ ) and $574.3 \AA$ (3d $\left.{ }^{1} \mathrm{D}-2 \mathrm{p}{ }^{1} \mathrm{P}^{0}\right)$ lines.

We also describe briefly our i.itial experiment which was conducted for one year before the modification of VUV spectrometer. In that experiment the VUV spectrometer viewed plasma as in Fig. 1; however, the air monochromator was located on the other side of the plasma and viewed it through another slit $S^{\prime}$, identical with the first one. Initially VUV and air monochromators with an electron multiplier and photomultiplier, respectively, monitored the time evolution of single spectral line intensities. The signals frr the CIV 312 $\dot{A}$ and $5801 \dot{A}$ lines were practically identical with FWHM $\sim 250-300$ nsec. Subsequently a multichannel detector was used in the VUV spectrometer (ime integrated signal); hence, the signal from the air monochromator was integrated in time in order to compare it with the VUV signal. Extremely careful and precise alignment was required to ensure that both instruments viewed exactly the same part of the plasma. The results were similar to the later results with improved instrumentation presented in Fig. 3.

The effect described here may provide an explanation of the disappearance of lines from transitions between levels with principal quantum number 4 and 3 in XUV spectra of high density plasmas $\left(N_{e}=10^{21}-10^{22} \mathrm{~cm}^{-3}\right.$ ) produced by the OMEGA laser (University of Rochester), in which lines from $4 \rightarrow 1$ transitions were very intense. ${ }^{6}$

The fact that the spontaneous emission coefficient is not constant as we used to think about it may be found in recent work on inhibition of spontaneous emission of an atom in a 
cavity which has no modes at the transition frequency ${ }^{7}$ and in studies of cyclorron radiation of an electron confined in a Penning trap, ${ }^{8}$ and a similar effect predicted in solid state cavities. ${ }^{9}$

In order to explain the experimental results, the Schrödinger equation was solyed numerically for CIV ions in the electric potential of surrounding plasma. This potentiat was approximated by using Debye radius $\mathrm{r}_{\mathrm{D}} \propto \mathrm{N}_{e} \cdot 1 / 2$, assuming $\mathrm{T}_{\epsilon}$, the electron temperature, to be constant. The transitions of the valence electron were assumed to occur in the internal potential of two bound electrons (is ${ }^{2}$ ), approximated by a uniform cloud of radius $R_{0}$ and influenced by the external field. The potential V(r) was therefore approximated by

$$
V(r)= \begin{cases}{\left[Z^{\prime} e^{2} / 2 R_{0}\left(3-\left(r / R_{0}\right)^{2]}-Z e^{2 / r}\right] \exp \left(-r / r_{D}\right)\right.} & r \leq R_{0} \\ -\left[(Z-Z) e^{2} / \tau\right] \exp \left(-r / r_{D}\right) & r>R_{0}\end{cases}
$$

where $e$ is electron charge, $r$ is distance from the center of the cloud, $Z^{\prime}=2$ and $Z=6$ for $C \Gamma V$ and $r_{D}$ was taken to be much larger than $R_{0}$.

Numerically solving the radial part of Schrödinger equation with potential $V(r)$, the wave functions and hence coefficients $A_{32}$ and $A_{31}$ were obtained. However, changes in the branching ratio predicted in this model were an order of magnitude smaller than those observed in the experiment for $\mathrm{N}_{\mathrm{e}} \approx 5 \times 10^{18} \mathrm{~cm}^{-3}$. A.lso, according to these calculations, significant shifts of spectral lines should cscur, which were not observed. This indicates, in agreement with discussion in Ref. 12, that any significant modification of A-coefficients may be due to variation of the transition strengths and not to the transition energy.

We also considered another model which predicts quenching of the spontaneous emission coefficients by collisions. For an unperturbed atom or ion the average time between radiative transitions is given as $\tau_{A}=1 / A$. If the frequency of coliisions of atoms or ions with, e.g., electrors, $v_{e i}=N_{e} S_{e j}\left(S_{e i}\right.$ is the rate of collisions), is such that $\tau_{e i}=$ 
$v_{e i}{ }^{-1} \ll<\tau_{A}$, then collisions may disrupt the process of spontaneous emission and may cause a decrease of the A-coefficients due to change of the transition strength ${ }^{12}$. In this case, the line intensity will become proportional to the new A-coefficient which depends on the collisional frequency. This is to be distinguished from the Lorentz model of line broadening in which collisions disturh the phase of the radiation but do not change the transition probability. In a pair of transitions, a stronger effect is expected for the transition with the smaller A-coefficient. Of course, population of the upper level is dependent on collisional processes; hence, to observe the effect of collisional quenching the branching ratio has to be measured as in our experiment.

Some indication of collisional quenching of sportaneous emission may be seen in observations of long wavelength forbidden lines in the ground configuration of highly ionized ions. 10 The spontaneous emission coefficients for such forbidden lines with $\lambda>$ $2000 \AA$ are usually in the range of $A=10^{2}-10^{3} \mathrm{sec}^{-1}$. Therefore, in this model, collisional quenching for these lines at $N_{e}=10^{14} \mathrm{~cm}^{-3}$ should be similar to lines with $A=10^{7}-10^{8}$ $\sec ^{-1}$ at $\mathrm{N}_{e}=10^{19} \mathrm{~cm}^{-3}$. Indeed it was noticed ${ }^{11}$ that for $\mathrm{N}_{e} \geq 10^{14} \mathrm{~cm}^{-3}$ it was impossible to observe the forbidden line $\mathrm{FeXX} 2665 \mathrm{~A}\left(\mathrm{~A}=5.7 \times 10^{\hat{2}} \mathrm{sec}^{-1}\right)$ in a tokamak plasma due to its very low intensity (this line was easily observed 10 at a lower density $\mathrm{N}_{e}=2 \times 10^{13}$ $\mathrm{cm}^{-3}$ ). Some difficulties in the observation of forbidden lines in higher density plasmas are related to the higher radiation background; however, the rise of the background is not sufficient to explain the disappearance of these lines.

The measurements of a variety of lines in a troad range of plasma parameters should help in the construction of the rigorous theoretical model for the prediction of quenching of spontareous emission coefficients in plasmas. 


\section{Acknowledgements}

We would like to thank H. Furth, U. Feldman. H. Griem, R. Kulsrud, T. Mclirath, J.L. Schwob, C. Skinner, T. Stix, J. Weisheit, A. Wouters, and E. Valeo for their commerts and stimulating discussions. We would also like to express our appreciation to H. Hirose for his help in the last stage of the experiment and to L. Guttadora and D. Dicicco for their technical assistance.

This work was supported by U.S. Department of Energy Advance Energy Project of Basic Energy Sciences, Contract No. KC-05-01. This work was performed at the Princeton Plasma Physics Laboratory, which operates under U.S. Deparment of Energy Contract No. DE-ACO2-76CHO3073. 


\section{Beferences}

${ }^{1}$ H. Griem, Plasma Suectroscopy, (McGraw-Hill, N.Y., 1964), p. 229

${ }^{2}$ D.R. Bates. A. Kingston, and R.W. MeWhirter,

Proc. R. Soc. Lordon, Ser. A: 267297 (1962).

${ }^{3}$ E. Hinilov and F. Hofman, J. Opt. Soc. Am. 531259 (1963).

${ }^{4}$ W.L. Wiess, M.W. Smith, and B.M. Glennon, Atomic Transition Probabilities,

(Vol. I, National Bureau of Standards, Washington, D.C., 1966), p. 45

${ }^{5}$ M.A. El-Farra and T.P. Hughes, J. Quant. Spectrosc. Radiat. Transfer 30, 335 (1983).

${ }^{6} \mathrm{U}$. Feldman, private communication.

${ }^{7}$ R.G. Hulet, E.S. Hiffer, and D. Kleppner, Phys. Rev. Leth. 55, 2137 (1985).

${ }^{8}$ G. Gabrielse and H. Dehmelt, Phys. Rev. Lett. 25,67 (1985).

${ }^{9}$ E. Yablonovitch, Phys, Rev. Lett. 58, 2059 (1987).

${ }^{10}$ S. Suckewer and E. Hinnov, Phys. Rev. Lett, 41,756 (1978).

${ }^{11} \mathrm{E}$. Marmar and J. Terry, privare communication.

12 J. C. Weisheit, Atomic Phenomena in Hot Dense Plasmas, in Applied Atomic Collision Physics (eds. H.S.W. Massey, E.W. McDaniel, and B. Bederson), vol. 2, (Academic Press, IN,Y, 1984) . 


\section{Eigure Cantions}

Fig. 1 Experimental situr.

Fig. 2 Example of spectra in the vicinity of (a) CTV $312 \dot{A}$ and (b) CVV $5801-5812 \dot{A}$ lines at distance from target $d=0.2 \mathrm{~mm}$ and $1.0 \mathrm{mrn}$.

Fig. 3 Branching ratio $I_{\text {VTS }} / I_{V U V}$ for CTV 5801-5812 $\AA$ and $31 \Sigma \AA$ lines as a function of distance $d$ and electron density for target width $w=0.35,0.42,1.0$, and 4.1 mim. The top corve comesponds to $\mathrm{I}_{\mathrm{VIS}} / \mathrm{I}_{\mathrm{VUV}}$ (multiplied by 1.4) as a function of target width w (approximately the widin of the plasma) for $d=0.5 \mathrm{~mm}$. 
\#87X0633
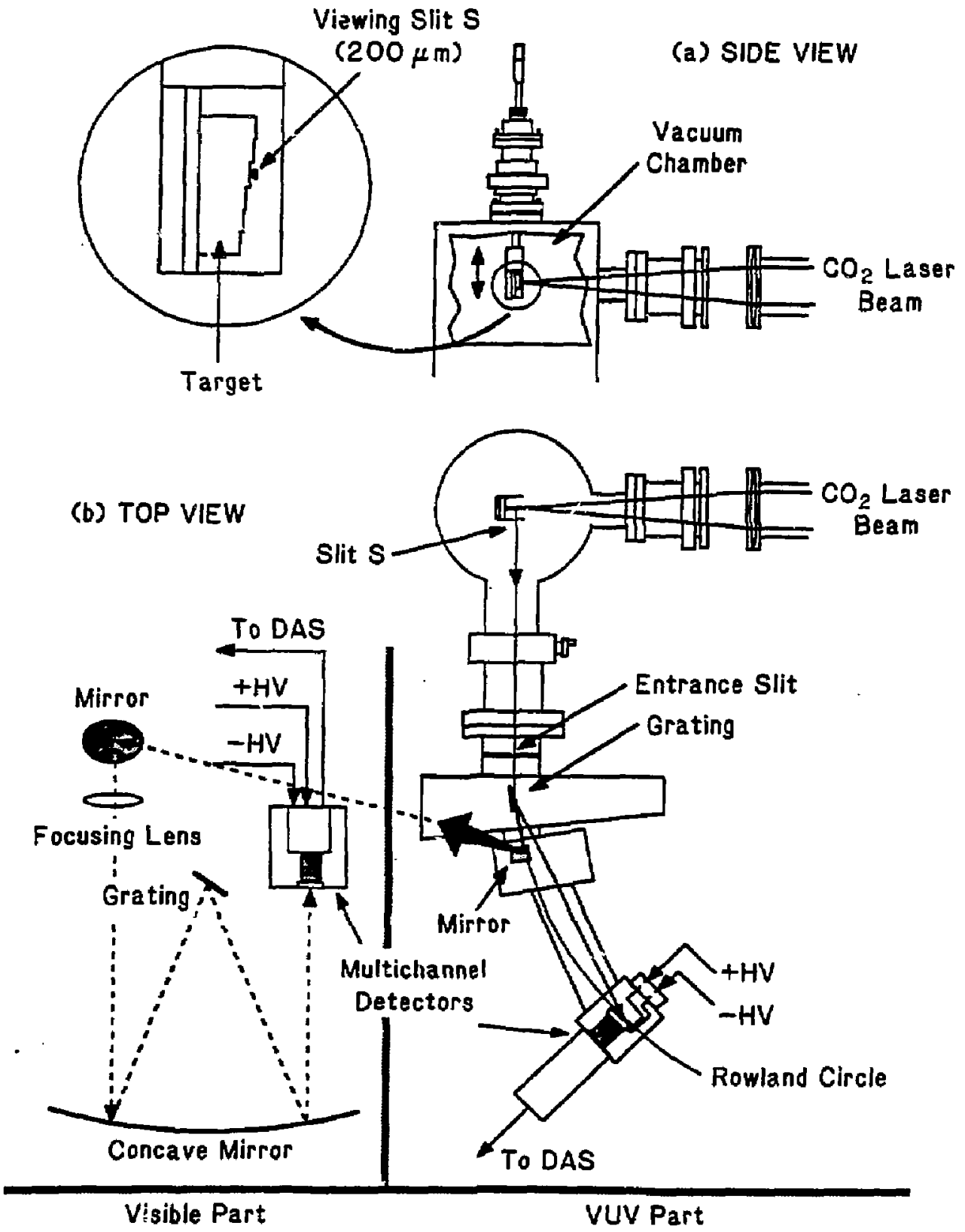

Fiq. 1 


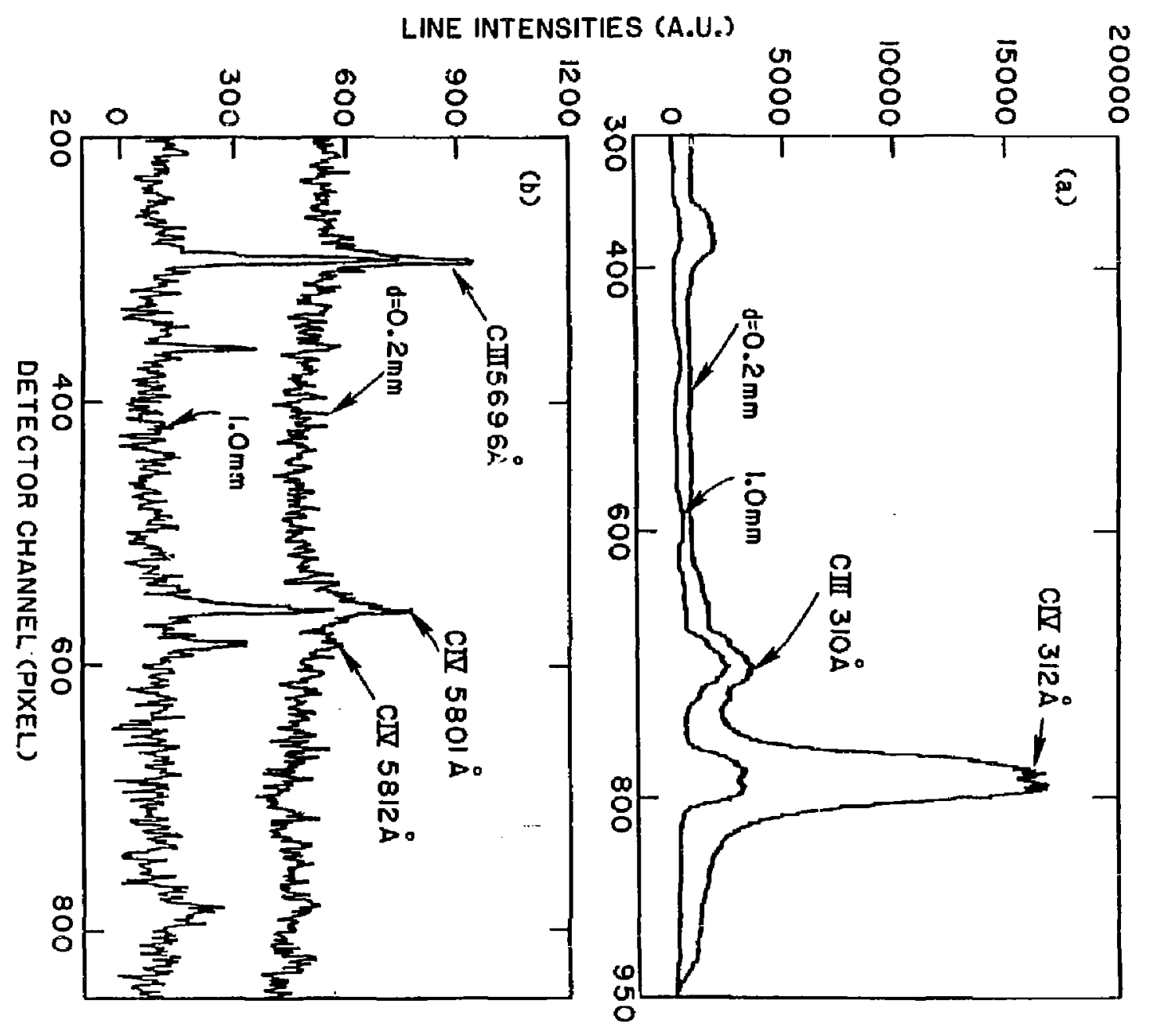


TARGET WIDTH $W(\mathrm{~mm})$

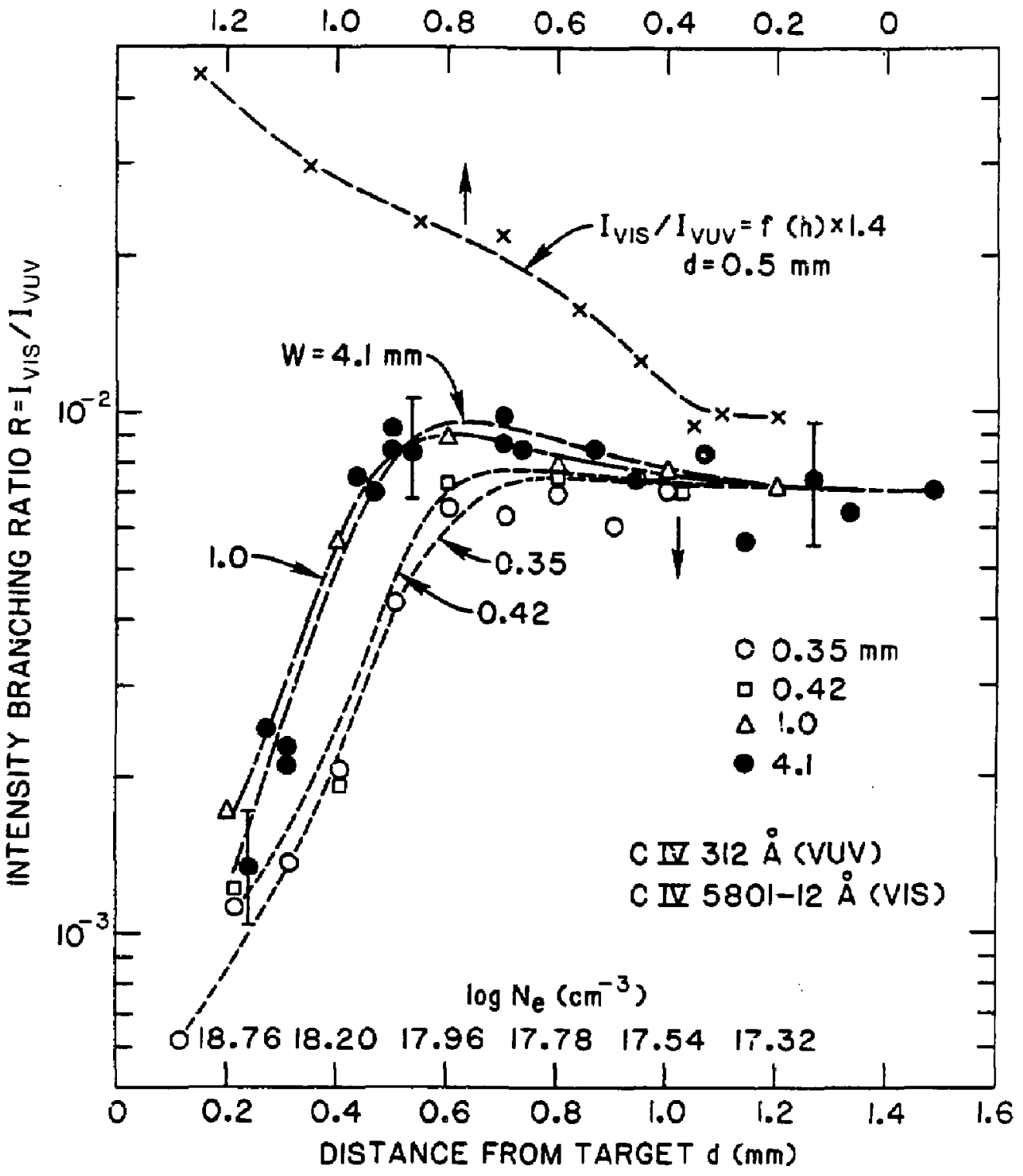

Fiq. 3 
Dr. Frank J. Paolonl, Unlv of wollongeng, AUSTRALIA Prol. M.H. Bronnan, Univ Sydney, Australis

Pl zsma Rescarch Lab., Australlion Nat. Un!V., AUSTRALiA

Prof. I,R, Jones, FI Inders UnIV., NUSTRALIA

Prof, F, Cap, Inst Theo Phys, Austric

Prof. M. Helndler, Institut fur Theoretische Physlk, AUSTRIA

M. Goossens, Astronomisch instltuut, BELGIUM

Ecole Royale Mlitelre, Lab de Phys Plashas, BELGlum

Com, of Europosn, Dg XII Fusion Prog, EELGIUM

Prof. R. Bouclque, Laboratorlum yoor Natuurkunde, BELGIUA

Dr. P.H. Sakanaka, Univ Estadual, ERazIL

Instituto de Pesqulsos Espactost-IMPE, ERUIL

Llbrary, stonic Energy of Conodo Limited, CMNDA

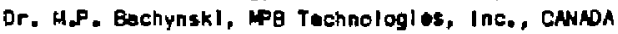

Dr. H.H. Skarsgard, UnIV of Saskatchuan, CAHNDA

Or. H. Bornard, Untversity of Britlsh Columbla, CANAOA

Prof. J. Telehmann, UnIV, of Montraal, Cawho

Prof. S.R. Sreenlvasan, Unlverslity of Calgary, CNADA

Prof. Tudor ki. Johnston, INR5-Energle, CANADA

Dr. C.R. Jemes, UnlY, of Alberta, CANAOA

Dr. Pater Lukse, Komenskoho UnIV, CzectostovaKIA

The Librarian, Culhom Laboratory, ENGLND

Mrs. S.A. Hutehineon, JET LJorary, ENGLAND

C. Mouttet. Leb. de Physique des All lleux tonlsés, Frawce

1. Rodot, CEM/CADARACHE - Bot 506. FRAHCE

Dr. Tom Wul, Acadeny Blollographic, how KDWG

Preprint Library, Cent fes Inst Phys, Hahgary

Dr. B. Dasgupte, Sahe Inst, InolA

Dr. R.K. ChhaJlanl, VIkran Unlv, IKolA

Dr. P. Kow, Institute tor Plasw Research, INDIA

Dr. PhIllip Rosenau, I sreal Inst Tech, ISRAEL

Prot. S. Cuparaten, TAI Aulv University, ISRAEL

LIbrarlon, Int'l Cer Theo Phys, ITALY

Prof. G. Rostognl, Unlv DI Padova, ITALY

miss clelio De Palo, Astoc EURATOH-EREA, ITALY

BIDlloteca, del CNR EURATOM, ITNY

Dr. H. Yomato, Toshlba Res \& Dov, JAPN

Prof. I. Kewakomi, Atomite EnorgY Ros. Institute, JAPNH

Prot. Kyojl NIshlkowa, Unle of HIroshima, JAPN

Direc. Dept. Lg. Tokanak Res. JAERI, JAPAN

Prot, Satoshl Itoh, Kyushu Unlvarsity, JAPAK

Pinsearch Info Cantar, Nagoyo Unluersity, JAPAN

Prof. S. Tanaka, Kyoto Unlyersity, JAPAN

Llbrary, Kyoto Univarsity, JAPA

Prof. Nobuyuki Inoue, University of Takyo, JAPAN

S. Mor I, JAERI, JAPAN

M.H. KIm, Kores Advanced Energy Research Institute, KOREA

Prot. D.1. Chol, Adv. Inst Sel t Tech, KOREA

Prof. 0.5. Llioy, University of walkato, MEW ZEALANO

Institute of Plasma Physics, PEOPLE'S REPUBLIC OF CHSNA

Llorarlon, Institute of Fhys... PEOPLE'S REPUELIC CF CHINA

LIbrary, Tsing HW Unlvai'slty, PEOPLE'S REPUELIC OF CHINA
2. L1, Southwest Inst, Physles. PEOPLE'S REPLALIC OF CHINA Prof. J.A.C. Cabrol, I nst Suparlar Teen, PORTUGAL

Or. Octavlan Potrus, AL I CUzs Unlversity, ROMNilA

Dr. Johan de villiers, Plasme Physies, AEC, SO AFRICA

Prof. MoA. Helloerg, University of Natol, SO AFRICA

Fusion Div. LI brary, JEN, SPhtN

Dr. LoAnert Stanflo, Univarslty of UMEA, SWEDEN

Llbrary, Royal I nst Twch, SWEDEN

Prot. Wans WI inel mo on, Chalmars Unir Tweh, SWEOEN

Contre Phys des Plasmes, Ecole Polytech Fod, SWITZERLAND

Gibll athedk, Fom-I net Voar PIagna-Fys/co, THE NETHERLANDS

Dr. DD. Ryutov, SIberton Aced Sel, USSR

Dr. G.R. EIIseav, Kurehetor InstItute, USSR

Dr. $V, R_{*}$ Glukhlikh, Inst Elactro-Physleal, USSR

Dr. Y.T. Tolok, inst. Phys. Toch, USSR

Dr. L.M. Kovrlzhnykh, Institute Gen. Physles, UȘSR

Prof. T.J.M. Boyd, Unlv College $N$ Wales, WAtes

Nuelear Res, Establishment, Julleh Lta., H. GERMAHtY

Blbllothek, Inst. Fur Plesingforsehung, W. GERMNY

Or. K. Schindlior, Ruhr Unlversltat, W. GERyyyY

ASDEx Reoding Rm, IPP/Mox+PIanck-I institut fü

Plasmaphyslk, W. GERHAYY

LIbrarlon, Max-Plonck Institut, W. GERMAwY

Prof, Rok. Janew, Inst Phys, Yugoslavia 